\title{
Pengaruh Kinerja Bauran Pemasaran Jasa kesehatan \& Lingkungan Eksternal Individu terhadap Citra Rumah Sakit Paru Dr.H.A. Rotinsulu
}

\author{
Ence Ihlasuyandi \\ Poltekkes Kemenkes Bandung, Indonesia \\ Email: ihlasuyandi@gmail.com
}

\begin{abstract}
Abstrak
Persaingan antar Rumah Sakit terus berkembang seiring dengan perubahan-perubahan yang terjadi baik regional maupun internasional. Paru Dr.H.A.Rotinsulu merupakan Rumah Sakit khusus pelayanan kesehatan penyakit paru perlu meningkatkan citra rumah sakit dalam persepsi pelanggan sebagai wakil dari masyarakat. Untuk meningkatkan citra tidak terlepas dari pengelolaan rumah sakit melalui program bauran pemasaran yang telah dilaksanakan dan pengaruh lingkungan eksternal individu pasien yang merupakan bagian terdalam (inti) dari perilaku pelanggan. Tujuan penelitian ini untuk mengungkapkan tanggapan pasien terhadap kinerja bauran pemasaran dan citra RS.Paru Dr.H.A. Rotinsulu serta pengaruh lingkungan eksternal individu pasien terhadap keberadaan/eksistensi RS. Paru Dr.H.A. Rotinsulu. Penelitian yang dilakukan bersifat deskriptif dan verifikatif dengan metode penelitian survey dengan pendekatan cross sectional. Cara pengambilan sampel dengan menggunakan random sampling, jumlah sampel dalam penelitian ini adalah 100 responden. Adapun teknik pengumpulan data yang digunakan adalah wawancara, observasi, kuesioner dan studi pustaka sedangkan teknik analisa data yang digunakan adalah berbentuk grafik dan analisis jalur ( Path Analysis ). Hasil penelitian menunjukkan bahwa secara umum kinerja bauran pemasaran dan citra RS. Paru Dr.H.A. Rotinsulu dirasakan oleh pelanggan baik, tetapi ada dua kinerja bauran pemasaran yang dirasakan kurang yaitu lokasi dan promosi. Lingkungan eksternal individu mempunyai pengaruh kuat terhadap pertimbangan menggunakan pelayanan di RS. Paru Dr.H.A. Rotinsulu. Secarabersama-sama kinerja bauran.
\end{abstract}

Kata Kunci: bauran pemasaran jasa, citra rumah sakit

\section{The effect of health services mixed marketing performance and individual external environment on the image of Dr.H.A Rotinsulu lung Hospital}

\begin{abstract}
The competitions among hospital develop continuously in lieu to regionally and internationally changing. To enhance public access to hospital, modern and professional hospital management is needed, so that the community can choose and bring hospitals to a better performance. $\mathrm{Dr} H . A$ Rotinsulu Lung Hospital as a specific hospital has to enhance its performance in relation to the community point of view. To enhance its performance the hospital management has to put into consideration the existing health services mixed marketing performance and the individual external environment as part of customer's behavior. Research also done to analyze the effect of health services mixed marketing performance and individual external environment on the image of Dr.H.A Rotinsulu Lung Hospital. Research used descriptive and verificative cross sectional research method. Research sample taken by simple random sampling method, the number of samples were 100 respondent, data collected through interviewing, observation, questionnaire and literature study, while data analyzing done through graphs and path analysis. Research result found that in general health services mixed marketing performance and the image of Dr.H.A Rotinsulu Lung hospital form the customer point of view is good, but there were two part of health services mixed marketing performance considered fair which was the location and promotion. The Individual external environment has physically powerful impression in using Dr.H.A Rotinsulu Lung hospital health services. Confluence of health services mixed marketing performance and the individual external environment bring about $65 \%$ to the performance of Dr.H.A Rotinsulu Lung Hospital, while 35\% were causative of other factors which not included in this research.
\end{abstract}

Keywords: mixed marketing performance, individual external environment

Received:25/08/2019; published: 1/10/2019

Indonesian Journal of Hospital Administration Vol. 2 No.2 


\section{PENDAHULUAN}

Salah satu strategi untuk mewujudkan Visi Kementerian Kesehatan yaitu Masyarakat gang Mandiri untuk Hidup Sehat adalah meningkatkan akses masyarakat terhadap pelayanan kesehatan yang berkualitas, hal ini sesuai dengan Rencana Strategis Kementerian Kesehatan. Peningkatan akses dan kualitas pelayanan kesehatan tersebut perlu didukung oleh pelaksanaan manajemen pelayanan kesehatan, peraturan perundang-undangan yang memadai, serta penelitian dan pengembangan kesehatan (1).

Dalam Sistem Kesehatan Nasional (SKN) terdapat subsistem upaya kesehatan yang memperjelas mengenai bentuk-bentuk pelayanan kesehatan di Indonesia. Subsistem Upaya kesehatan tersebut dibagi menjadi dua bagian yaitu Upaya Kesehatan Masyarakat (UKM) dan Upaya Kesehatan Perorangan (UKP). UKM lebih menitikberatkan kepada pelayanan kesehatan yang besifat promotif dan preventif, sedangkan UKP lebih menitikberatkan pelayanan kesehatan yang bersifat kuratif dan rehabilitatif.

Rumah Sakit termasuk ke dalam bentuk Upaya Kesehatan Perorangan (UKP) dan merupakan mata rantai dalam pelayanan kesehatan di Indonesia yang mempunyai fungsi utama menyelenggarakan upaya peningkatan kesehatan yang bersifat penyembuhan dan pemulihan penderita.

Meningkatnya peran serta swasta dalam pelayanan kesehatan mengakibatkan semakin ketatnya persaingan antara Rumah Sakit, hal ini mendorong Rumah Sakit Pemerintah melangkah kearah profesionalisme, efisiensi dan efektivitas dari berbagai kegiatan operasional dan manajemennya. Dengan disahkannya UU No.1 Tahun 2004 tentang Perbendaharaan Negara, di mana dalam UU tersebut ada hal yang dapat disangkutpautkan dengan organisasi Rumah Sakit Pemerintah yaitu mengenai pengelolaan keuangan Badan Layanan Umum (BLU) diperkuat juga dengan kebijakan pengelolaan keuangan untuk jaminan kesehatan masyarakat miskin diserahkan kepada pihak ke III yaitu BPJS Kesehatan, sehingga perubahan-perubahan tersebut menuntut Rumah Sakit Pemerintah untuk lebih meningkatkan daya saing dan daya tarik pasar sasarannya.

Rumah Sakit Paru Dr. H.A. Rotinsulu Bandung yang secara organisatoris merupakan unit pelayanan teknis vertikal dibawah Kementerian Kesehatan RI yang awalnya merupakan Rumah Sakit Khusus Tuberkulosa Paru kemudian tepatnya pada tanggal 26 Februari 2004 berubah menjadi Rumah Sakit Paru.

Berdasarkan Peraturan Menteri Kesehatan Republik Indonesia Nomor 250/MENKES/Per/III/2018 tentang Organisasi dan Tata Kerja Rumah Sakit Paru dalam pasal 2 menyebutkan bahwa Rumah Sakit Paru mempunyai tugas melaksanakan pelayanan kesehatan terhadap penderita penyakit paru secara menyeluruh, terpadu, dan berkesinambungan, pendidikan dan pelatihan serta penelitian dan pengembangan di bidang penanggulangan penyakit paru sesuai dengan peraturan perundang-undangan yang berlaku. 
Perubahan tersebut seharusnya mempunyai dampak terhadap peningkatan utilitas rumah sakit dikarenakan terjadi penambahan cakupan jenis pelayanan dari hanya bisa menangani penyakit tuberkulosa paru (TB Paru) menjadi bisa lebih banyak menangani kasus paru lainnya (Non TB Paru). Persaingan dalam menangani penyakit paru sangat ketat, dikarenakan bukan hanya rumah sakit khusus paru yang bisa menangani penyakit paru tetapi Puskesmas, BKPM dan Rumah Sakit Umum juga bisa menangani penyakit tersebut. Sehingga untuk bisa lebih meningkatkan daya saing dan daya tarik Rumah Sakit Paru diperlukan peningkatan kualitas pelayanan dalam penanganan penyakit paru kepada masyarakat dan diperlukannya kerjasama dengan Puskesmas, BKPM dan Rumah Sakit-Rumah Sakit Umum di Jawa Barat dalam rangka menempatkan sebagai pusat rujukan penanganan penyakit paru di Jawa Barat.

Rumah Sakit Paru Dr. H.A. Rotinsulu telah mencoba melakukan perbaikan-perbaikan atau melakukan strategi-strategi untuk meningkatkan utilitas dan efisiensi pelayanannya melalui program pemasaran berupa bauran pemasaran diantaranya membuat perencanaan induk (Master Plan) yang didalamnya ada perencanaan pembangunan fisik rumah sakit, membuka dan mengembangkan jenis pelayanan, melakukan differensiasi produk contohnya program pasien hantar untuk kunjungan rawat jalan, melakukan pelayanan pro-aktif dengan cara mendatangi pasien langsung ketempat contoh : melakukan foto thoraks dengan memanfaatkan Mobile X-ray, pembinaan Puskesmas, penyuluhan di RRI \& tempat-tempat lainnya misalnya sekolah-sekolah hal ini diharapkan semakin dikenalnya rumah sakit oleh masyarakat, pengembangan pendidikan \& pelatihan bagi karyawan sehingga diharapkan mempunyai pengetahuan dan moralitas yang tinggi, dan program-program lainnya yang berkaitan dengan unsur-unsur dalam bauran pemasaran

Kinerja bauran pemasaran tersebut diharapkan dapat meningkatkan kualitas pelayanan sehingga dapat menciptakan kepuasan bagi pasien. Apabila pasien merasa puas dengan bauran pemasaran yang diberikan oleh pihak rumah sakit maka mereka (pasien) akan melakukan pemanfaatan jasa kesehatan yang berulang-ulang, di samping itu mereka cenderung akan saling memberitahukan dari mulut ke mulut (word of mouth communication) kepada relasi-relasi terdekatnya, agar mereka melakukan hal yang sama dengan dirinya, yakni memanfaatkan jasa kesehatan di rumah sakit yang sama. Penyakitparu secara umum mempunyai kesan dimasyarakat adalah penyakit menular berbeda dengan penyakitkhusus Jantung \& Pembuluh Darah dan Rumah Sakit Umum lainnya, hal ini dikarenakan informasi yang didapat dari lingkungan membentuk persepsi seperti tersebut. Selain itu banyak masyarakat beranggapan bahwa orang yang menderita penyakit TB. Paru perlu diisolasi, informasi seperti itulah akan mempengaruhi dalam diri individu pasien untuk memutuskan berobat ke Rumah Sakit Paru.

Keluhan masyarakat terhadap rumah sakit semakin banyak dan mudah sekali tersebar melalui media cetak dan elektronik, terutama masalah kepuasan dan kenyamanan, Oleh sebab itu rumah sakit dituntut untuk meningkatkan citra ke arah lebih baik. Meningkatkan citra rumah sakit 
dalam kondisi persaingan seperti ini adalah merupakan tuntutan yang harus segera dilaksanakan, karena pada dasarnya, melalui terpeliharanya citra yang baik, maka rumah sakit akan senantiasa dapat melaksanakan tugas dan fungsi sesuai dengan tujuan yang ingin dicapai.

Penyakit paru di masyarakat mempunyai citra menular dan mengingat RS. Paru Dr. H.A. Rotinsulu sebagai rumah sakit Pemerintah yang identik dengan kualitas pelayanan yang Kurang Baik, maka perlu dipertimbangkan lingkungan eksternal individu pasien sebagai wakil dari masyarakat sebagai faktor yang menentukan perilaku pelanggan selain faktor internal, sehingga diharapkan secara bersama-sama kinerja bauran pemasaran dan faktor lingkungan eksternal individu dapat mempengaruhi citra Rumah Sakit Paru Dr. H.A. Rotinsulu kearah yang lebih baik sebagai respon terakhir dari pemanfaatan jasa kesehatan Rumah Sakit Paru. (17)

Untuk menjawab keingintahuan seperti yang dikemukakan diatas maka diperlukan suatu penelitian yang dapat menyingkap kinerja bauran pemasaran, perilaku pasien terutama yang dipengaruhi oleh faktor lingkungan eksternal individu dan sejauh mana citra Rumah Sakit Paru Dr.H.A. Rotinsulu dimata pasien sebagai wakil dari masyarakat, selain itu perlu diketahui adanya pengaruh kinerja bauran pemasaran dan faktor lingkungan eksternal individu pasien terhadap citra Rumah Sakit Paru Dr.H.A.Rotinsulu. Melalui penelitian ini diharapkan dapat dijadikan bahan evaluasi dan sekaligus dapat menggali temuan-temuan di lapangan yang dapat dijadikan dasar bagi pihak manajemen Rumah Sakit Paru Dr. H.A. Rotinsulu dalam rangka membentuk, mempertahankan maupun meningkatkan citra institusinya sehingga akhirnya berdampak kepada peningkatan kualitas pelayanan.

\section{BAHAN DAN METODE}

Metode penelitian yang digunakan adalah metode deskriptif survey dengan pendekatan cross sectional. Rancangan penelitian bersifat deskriptif verifikatif. Deskriptif bertujuan untuk memperoleh deskripsi ciri-ciri variabel tanggapan pasien terhadap kinerja bauran pemasaran jasa kesehatan, lingkungan eksternal individu dan citra RS. Paru Dr. H.A. Rotinsulu. Verifikatif bertujuan menguji kebenaran suatu hipotesis yang dilaksanakan melalui pengumpulan data di lapangan mengenai pengaruh kinerja bauran pemasaran jasa kesehatan dan lingkungan individu terhadap citra RS. Paru Dr. H.A. Rotinsulu. Penelitian ini akan menganalisa pengaruh kinerja bauran pemasaran jasa kesehatan dan lingkungan eksternal individu terhadap citra RS. Paru Dr. H.A. Rotinsulu.

Dalam penelitian ini yang menjadi variabel bebas (independent variabel) adalah kinerja bauran pemasaran jasa kesehatan dan lingkungan eksternal individu. Khusus untuk bauran pemasaran mempunyai sub variabel produk atau jasa, tarif, lokasi, promosi, sumber daya manusia, sarana fisik, dan proses. Sedangkan variabel terikat (dependent variabel) adalah citra RS. Paru Dr. H.A. Rotinsulu. Operasionalisasi variabel penelitian yang menganalisa pengaruh kinerja bauran 
pemasaran jasa kesehatan dan lingkungan eksternal individu terhadap citra RS. Paru Dr. H.A. Rotinsulu Unit analisis atau populasi penelitian ini adalah masyarakat umum yang menggunakan jasa pelayanan kesehatan di RS. Paru Dr. H.A. Rotinsulu baik rawat jalan maupun rawat inap dengan membayar sendiri selama dilakukannya penelitian

Untuk menentukan besarnya pengaruh kinerja bauran pemasaran jasa kesehatan dan lingkungan eksternal individu terhadap citra Rumah Sakit Paru Dr. H.A. Rotinsulu, digunakan pendekatan penelitian melalui analisa jalur (Path Analysis). Besarnya pengaruh antara suatu variabel penyebab ke variabel akibat disebut dengan koefisien jalur. Koefisien jalur pada dasarnya merupakan koefisien korelasi, maka ukuran sampel minimal untuk analisis jalur ini, dapat ditentukan melalui rumus ukuran sampel minimal untuk koefisien korelasi secara iteratif. Dalam penarikan sampel dalam penelitian ini diawali dengan membagi jumlah sampel (100 orang responden) menjadi dua bagian yaitu 70 orang responden dari rawat jalan dan 30 orang responden dari rawat inap, hal ini berdasarkan pertimbangan bahwa pasien dirawat inap lebih lama berintekrasi dengan pelayanan Rumah Sakit dibanding pasien rawat jalan sehingga tidak bisa dihitung secara proporsional dengan jumlah pasien di rawat jalan, maka ditetapkan sampel minimal pada penelitian sosial yaitu 30. Tehnik penarikan sampel dirawat jalan menggunakan systematic random sampling yaitu pengambilan sampel dilakukan secara berurutan dengan interval tertentu. Besarnya interval (i) dapat ditentukan dengan membagi populasi $(\mathrm{N})$ di rawat jalan dengan jumlah sampel yang diinginkan $(n=70)$ atau $i=N / n$ atau $441 / 70=6,3$ dibulatkan

menjadi 7, Jadi penarikan sampel secara berurutan dengan interval 7. Penarikan sampel pertama dilakukan secara acak sederhana dari nomor 1 sampai dengan besarnya interval. Rata-rata pasien bayar sendiri di rawat jalan perhari adalah sebanyak 18 orang dengan interval 7 maka setiap hari akan didapatkan 2 sampai 3 responden. Sedangkan tehnik penarikan sampel di rawat inap menggunakan stratified random sampling dengan cara sebagai berikut:(1) mendata jumlah pasien bayar sendiri pada masing-masing kelas (2) menghitung jumlah sampel untuk masingmasing kelas dengan menggunakan rumus : $\mathrm{ni}=\mathrm{Ni} / \mathrm{N} \times 30 ; \mathrm{ni}=$ besarnya sampel pada strata ke-I, $\mathrm{Ni}=$ besarnya populasi pada strata ke-I dan $\mathrm{N}=$ besarnya populasi secara keseluruhan.

\section{HASIL DAN PEMBAHASAN}

Melalui penelitian ini diharapkan dapat dijadikan bahan evaluasi dan sekaligus dapat menggali temuan-temuan di lapangan yang dapat dijadikan dasar bagi pihak manajemen Rumah Sakit Paru Dr. H.A. Rotinsulu dalam rangka membentuk, mempertahankan maupun meningkatkan citra institusinya sehingga akhirnya berdampak kepada peningkatan kualitas pelayanan. Penelitian ini dengan judul Pengaruh Kinerja Bauran Pemasaran Jasa kesehatan \& Lingkungan Eksternal Individu terhadap Citra Rumah Sakit Paru Dr.H.A. Rotinsulu. Hasil penelitian berdasarkan 
karakteristik responden berdasarkan umur, Jenis Kelamin, Pendidikan, pekerjaan, distribusi frekuensi dapat dilihat pada tabel berikut:

Tabel 1 Karakteristik Responden

\begin{tabular}{lc}
\hline \multicolumn{1}{c}{ Karakteristik } & Frekuensi \\
\hline Usia & \\
$\leq 20$ & 11 \\
$21-30$ & 41 \\
$31-40$ & 18 \\
$41-50$ & 19 \\
$>50$ & 11 \\
Jenis Kelamin & \\
Laki-laki & 59 \\
Wanita & 41 \\
Pekerjaan & \\
PNS & 7 \\
BUMN & 1 \\
Pegawai Swasta & 43 \\
Pelajar/Mahasiswa & 16 \\
Lain-Lain & 33 \\
Pendidikan & \\
SD/SMP & 24 \\
SMA & 47 \\
D3 & 13 \\
S1 & 15 \\
S2/S3 & 1 \\
\hline
\end{tabular}

Berdasarkan Tabel 1 pada hasil penelitian dengan judul Pengaruh Kinerja Bauran Pemasaran Jasa kesehatan \& Lingkungan Eksternal Individu terhadap Citra Rumah Sakit Paru Dr.H.A. Rotinsulu, di atas tampak bahwa kategori usia responden yang memiliki frekuensi terbanyak adalah mereka yang berusia 21-30 tahun yaitu sebanyak 41 responden ( $41 \%$ ). Kategori usia responden yang paling sedikit sebanyak 11 responden ( $11 \%$ ) adalah mereka yang berusia $\leq 20$ tahun dan $\geq 50$ tahun. Kalau dikaitkan dengan distribusi normal penduduk Kota Bandung ditinjau dari usia, memang yang paling banyak adalah usia 21-30 tahun.27 Usia 21-30 tahun ini merupakan usia produktif dan merupakan generasi muda yang akan melanjutkan pembangunan bangsa sehingga memerlukan tingkat kesehatan lebih baik.

Karakteristik responden berdasarkan jenis kelamin dari Tabel 1 diatas dapat terlihat bahwa sebagian besar responden adalah laki-laki sebanyak 59 responden (59\%) sisanya adalah wanita sebanyak 41 responden ( $41 \%$ ). Berdasarkan jenis pekerjaannya responden penelitian sangat beragam bidang pekerjaan, namun terlihat bahwa paling banyak pekerjaan responden adalah pegawai swasta sebanyak 43 responden ( $43 \%$ ), sedangkan yang paling sedikit adalah BUMN dan Pegawai Negeri Sipil yang melakukan iur bayar, yaitu sebanyak 1 dan 7 responden (1\% dan 7\%). Karakteristik responden berupa tingkat pendidikan terlihat bahwa sebagian besar responden berpendidikan SMU/SLTA sebanyak 47 responden (47\%) disusul urutan kedua sebanyak 24 
responden (24\%) berpendidikan SD/SLTP dan responden yang paling sedikit adalah S2/S3 sebanyak 1 responden (1\%).

Tabel 2 Rangkuman Rekapitulasi Tanggapan Responden

\begin{tabular}{lllll}
\hline \multicolumn{1}{c}{ Variabel } & $\begin{array}{l}\text { Total skor } \\
\text { terkecil }\end{array}$ & $\begin{array}{l}\text { Total skor } \\
\text { terbesar }\end{array}$ & $\begin{array}{l}\text { Nilai } \\
\text { Kuantitatif }\end{array}$ & $\begin{array}{l}\text { Nilai } \\
\text { Kualitatif }\end{array}$ \\
\hline $\begin{array}{l}\text { Kinerja bauran pemasaran } \\
\text { Produk }\end{array}$ & 500 & 2500 & 1875 & Baik \\
Harga & 300 & 1500 & 1043 & Baik \\
Lokasi & 400 & 2000 & 1213 & Cukup \\
Promosi & 300 & 1500 & 963 & Cukup \\
SDM & 500 & 2500 & 1867 & Baik \\
Sarana Fisik & 400 & 2000 & 1369 & Baik \\
$\quad$ Proses & 300 & 1500 & 1053 & Baik \\
\hline Lingkungan & 400 & 2000 & 1439 & Kuat \\
eksternal individu & & & & \\
\hline Citra RS & 400 & 2000 & 1449 & Baik \\
\hline
\end{tabular}

Tabel 2 menunjukkan kinerja bauran pemasaran jasa kesehatan di RS. Paru Dr.H.A. Rotinsulu yang dirasakan oleh responden sebagian besar baik, sehingga perlu di pertahankan, sisanya masih dirasakan oleh responden cukup yaitu kinerja bauran pemasaran lokasi dan promosi, artinya kinerjanya termasuk dalam katagori kurang oleh karena itu perlu ditingkatkan menjadi lebih baik. Pengaruh lingkungan eksternal individu dalam menggunakan pelayanan di RS. Paru Dr.H.A. Rotinsulu yang dirasakan oleh responden pengaruhnya kuat, artinya keberadaan atau eksistensi RS. Paru Dr.H.A. Rotinsulu di masyarakat sudah baik. Citra RS. Paru Dr.H.A. Rotinsulu dirasakan oleh responden sudah baik, sehingga perlu dipertahankan.

Pengaruh kinerja bauran pemasaran jasa kesehatan \& lingkungan eksternal individu yang meliputi produk, harga, lokasi, promosi, manusia, sarana fisik, proses dan lingkungan eksternal individu (variabel bebas) terhadap citra RS. Paru Dr.H.A. Rotinsulu (variabel terikat) dapat diketahui dengan cara menghitung koefisien korelasi antar variabel dengan menggunakan rumus korelasi product moment, kemudian dilanjutkan dengan menghitung nilai besarnya keeratan pengaruh variabel bebas dengan variabel terikat yang disebut dengan koefisien jalur. Hasil perhitungan statistik dibawah ini hubungan struktural antara variabel produk (X1), harga (X2), lokasi (X3), promosi (X4), manusia (X5), sarana fisik (X6), proses (X7), lingkungan eksternal individu (X8) dan Citra RS. Paru Dr.H.A.Rotinsulu (Y) beserta nilai koefisien korelasi antar variabel bebas dan nilai koefisien jalur antara variabel bebas dengan variabel terikat juga antar variabel lain diluar penelitian dengan variabel terikat. 


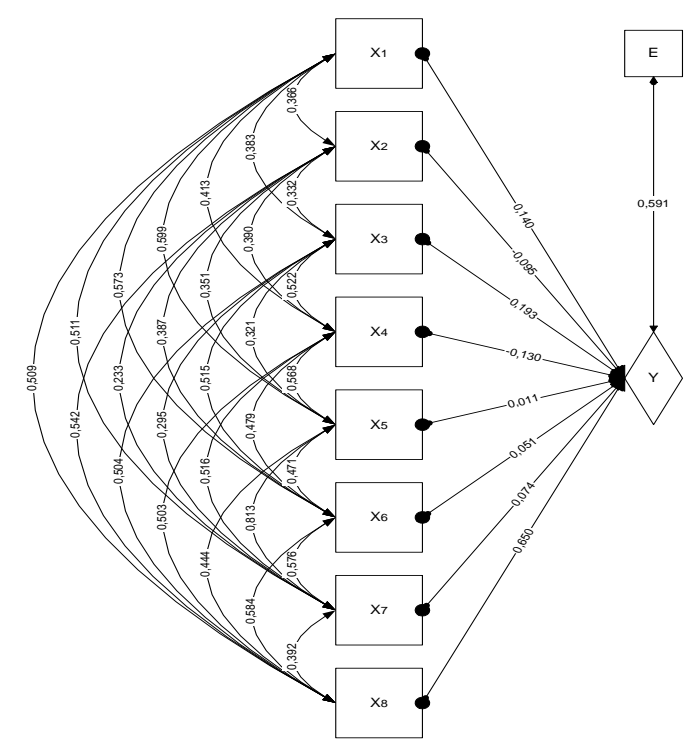

Gambar 1 Hubungan struktural antar variabel

Setelah koefisien jalur diperoleh, selanjutnya ditentukan besar pengaruh secara bersamasama dari kedelapan variabel bauran pemasaran jasa kesehatan dan lingkungan eksternal individu terhadap citra RS. Paru Dr.H.A. Rotinsulu yang disebut dengan koefisien determinasi (R2). Nilai koefisen determinasi (R2) dapat diinterprestasikan sebagai pengaruh variabel bebas terhadap variabel terikat. Berdasarkan hasil perhitungan nilai koefisien determinasi pada penelitian ini sebesar 0,651 ( $65 \%$ ), artinya dalam penelitian ini $65 \%$ citra RS. Paru Dr.H.A. Rotinsulu dipengaruhi oleh kinerja bauran pemasaran dan lingkungan eksternal individu, sedangkan sisanya sebesar $35 \%$ dipengaruhi faktor-faktor lain yang tidak ikut diteliti.

Berdasarkan perhitungan didapatkan nilai $F$ hitung sebesar 21,199 sedangkan nilai Ftabel atau $\mathrm{F0}, 05(8,91)=2,039$ (dari tabel distribusi $\mathrm{F}$ ), karena Fhitung > Fa (k,n-k-1), maka H0 ditolak pada tingkat signifikan 0,05 , jadi berdasarkan pada hasil pengujian maka dengan tingkat kepercayaan $95 \%$ dapat disimpulkan bahwa secara bersama-sama kinerja bauran pemasaran jasa kesehatan dan lingkungan eksternal individu berpengaruh terhadap citra RS. Paru Dr.H.A. Rotinsulu. Untuk memperoleh gambaran yang menyeluruh terhadap hasil pengujian hipotesis penelitian, dapat dilihat pada tabel berikut ini: Berdasarkan Tabel 3 dapat dijelaskan bahwa secara simultan kinerja bauran pemasaran dan lingkungan eksternal individu mempengaruhi citra RS. Paru Dr.H.A. Rotinsulu sebesar $65 \%$, sisanya dipengaruhi oleh faktor-faktor lain diluar penelitian (35\%). Dengan menggunakan derajat kepercayaan $95 \%$.

Apabila dirinci secara parsial terlihat bahwa yang memiliki pengaruh secara bermakna hanya dua variabel yaitu lokasi dan lingkungan eksternal individu. Pengaruh lingkungan eksternal individu paling dominan mempengaruhi citra RS. Paru Dr.H.A. Rotinsulu yaitu hampir setengahnya dipengaruhi oleh lingkungan eksternal individu $(51,24 \%)$ kemudian disusul dengan 
pengaruh kinerja bauran pemasaran; lokasi sebesar 9,88 \% mempengaruhi citra RS. Paru Dr.H.A Rotinsulu.

Tabel 3 Rangkuman Pengujian Hipotesis

\begin{tabular}{lll}
\hline Hipotesis Penelitian & Besarnya pengaruh & Keputusan \\
\hline Kinerja bauran pemasaran & $\mathrm{R} 2 \mathrm{y}(\mathrm{X} 1, \mathrm{X} 2, \ldots ., \mathrm{X} 8=0,651$ & $\mathrm{X} 1, \mathrm{X} 2, \ldots ., \mathrm{X8}$ \\
jasa kesehatan (produk, harga, & & $\begin{array}{l}\text { secara simultan } \\
\text { berpengaruh } \\
\text { terhadap } \mathrm{Y}\end{array}$ \\
lokasi, promosi, manusia, & & \\
sarana fisik, proses) dan \\
lingkungan eksternal individu
\end{tabular}

Memahami keinginan pasien sebagai pelanggan dari Rumah Sakit merupakan hal yang sangat penting apalagi Rumah Sakit bergerak dalam bidang jasa dengan karakteristikkarakteristik tertentu yaitu tidak berwujud, tidak terpisahkan, bervariasi dan tidak bisa disimpan, ditinjau dari kalisifikasi jasa, Rumah Sakit merupakan organisasi penyedia jasa kesehatan yang mempunyai high contact service dengan pelanggannya, berdasarkan karakteristik dan klasifikasi jasa tersebut perlu ada strategi-strategi khusus bagaimana keinginan pelanggan dapat terpenuhi melalui peningkatan kinerja bauran pemasaran . Hal ini berarti kinerja bauran pemasaran yang dirasakan oleh pasien agar lebih ditingkatkan kembali dari yang sudah baik menjadi sangat baik dan dari yang dirasakan cukup, kurang dan tidak baik menjadi baik bahkan sangat baik.

Peningkatan kinerja bauran pemasaran yang dirasakan cukup, kurang dan tidak baik perlu mendapat perhatian lebih, seperti halnya kinerja bauran pemasaran; lokasi dirasakan cukup, hal ini dikarenakan posisi RS. Paru Dr.H.A. Rotinsulu yang menjorok kedalam, akses langsung ke Rumah Sakit berupa jalan yang sempit dan macet ditambah tidak adanya alat transportasi umum yang melewati langsung ke RS. Paru Dr.H.A. Rotinsulu.

Untuk meningkatkan kinerja bauran pemasaran;lokasi ini perlu adanya perubahanperubahan, terutama dalam membenahi akses untuk mencapai lokasi rumah sakit melalui penyediaan alat transportasi dan menjalin kerjasama dengan instansi lain yang berwenang untuk mentertibkan kemacetan menuju jalan ke lokasi RS. Paru Dr.H.A.Rotinsulu. Dalam bidang jasa lokasi merupakan faktor kunci dalam memberikan pelayanan kepada pelanggan apalagi jasa kesehatan Rumah Sakit dengan kondisi pelanggan dalam keadaan sakit, memerlukan pelayanan segera dalam keadaan aman, nyaman, cepat dan mudah. 
Dalam melakukan peningkatan kinerja lokasi untuk memenuhi keinginan pelanggan perlu diperhatikan prinsip-prinsip lokasi ditinjau dari tingkat interaksi dengan pelanggan yaitu: pelanggan yang mendatangi penyedia jasa, penyedia jasa mendatangi pelanggan dan penyedia jasa dan pelanggan berinteraksi menggunkan perantara. Selain kinerja bauran pemasaran;lokasi, kinerja bauran pemasaran;promosi di RS. Paru Dr.H.A. Rotinsulu dirasakan cukup baik, hal ini bisa disebabkan kurang jelasnya pemberian informasi jenis-jenis pelayanan dan masih terbatasnya keanekaragaman media promosi. Dalam merancang promosi untuk mengkomunikasikan jasa kesehatan perlu mempertimbangkan karakteristik pelanggannya sehingga promosi yang dilakukan tepat dan dapat mencapai tujuan yang diinginkan.

Perilaku pelanggan salah satunya dipengaruhi oleh lingkungan eksternal individu, dalam penelitian ini dapat digambarkan secara kualitatif bahwa lingkungan eksternal individu yang terdiri dari budaya, kelompok acuan/tokoh, teman dan keluarga telah mempengaruhi responden untuk menilai dan memutuskan menggunakan jasa kesehatan RS. Paru Dr.H.A. Rotinsulu dirasakan kuat. Sama halnya dengan citra RS. Paru Dr.H.A. Rotinsulu telah dirasakan oleh responden sudah baik, pengukuran citra terdiri dari popularitas RS. Paru Dr.H.A. Rotinsulu dan kesan terhadap keberadaan Rumah Sakit dirasakan sudah baik, Kepercayaan dan keyakinan terhadap Rumah Sakit sudah yakin atau percaya dan keinginan untuk menggunakan kembali jasa kesehatan RS. Paru Dr.H.A. Rotinsulu dirasakan ingin kembali apabila mengalami penyakit yang sama.

Hasil uji analisis bivariat menggunakan uji korelasi kendall's tau menunjukkan ada hubungan pengetahuan perawat tentang morse fall scale dengan kepatuhan assesmen ulang risiko jatuh di ruang rawat inap RSUD Wates dengan nilai $p$ value $=0,01$ ( $p$ value $<0,05$ ) yang artinya terdapat hubungan yang bermakna pengetahuan perawat tentang morse fall scale dengan kepatuhan assesmen ulang risiko jatuh. Adanya hubungan pengetahuan tentang morse fall scale dengan tingkat kepatuhan assesmen ulang risiko jatuh berarti variabel pengetahuan yang menurut teori semakin tinggi pengetahuan akan semakin patuh dalam melaksanakan assesmen ulang risiko jatuh dan prosedur keselamatan pasien patient safety akan meningkat.

\section{SIMPULAN DAN SARAN}

Kinerja bauran pemasaran jasa kesehatan yang terdiri atas produk, harga, lokasi, promosi, manusia, sarana fisik dan proses di RS. Paru Dr.H.A. Rotinsulu secara umum memiliki kinerja baik, tetapi ada dua kinerja bauran pemasaran memiliki kinerja kurang yaitu lokasi dan promosi, hal ini disebabkan karena RS. Paru Dr.H.A. Rotinsulu sulit dijangkau dan kurang dikunjungi oleh transportasi umum, demikian juga karena kurang jelasnya penyampaian informasi jenis pelayanan dan media promosi yang masih terbatas. 
Tanggapan pasien mengenai citra RS. Paru Dr.H.A. Rotinsulu secara kualitatif dirasakan baik, karena pasien sudah merasakan RS. Paru Dr.H.A. Rotinsulu telah dikenal, kesan yang baik mengenai keberadaan RS. Paru Dr.H.A. Rotinsulu, adanya kepercayaan/keyakinan terhadap pelayanan yang diberikan di RS. Paru Dr.H.A. Rotinsulu dalam menyelesaikan masalah pasien dan adanya keinginan untuk kembali menggunakan jasa kesehatan RS. Paru Dr.H.A. Rotinsulu apabila terjadi masalah yang sama. Meskipun demikian tetap masih perlu adanya peningkatan citra RS. Paru Dr.H.A. Rotinsulu secara bertahap dan berkelanjutan menuju nilai yang optimal. Perilaku pelanggan yang dipengaruhi faktor lingkungan eksternal individu yang terdiri atas budaya, kelompok acuan, teman dan keluarga secara umum dirasakan kuat dalam menilai dan memutuskan menggunakan jasa kesehatan RS. Paru Dr.H.A. Rotinsulu atau dengan bahasa lain faktor lingkungan eksternal individu dirasakan sudah memberikan kontribusi terhadap keberadaan/eksistensi RS.Paru Dr.H.A. Rotinsulu.

Kinerja bauran pemasaran jasa kesehatan dan lingkungan eksternal individu secara simultan berpengaruh bermakna terhadap citra RS. Paru Dr.H.A. Rotinsulu. Secara parsial hanya ada dua variabel yang berpengaruh secara bermakna yaitu lingkungan eksternal individu dan kinerja bauran pemasaran;lokasi. Pengaruh kinerja bauran pemasaran lainnya tidak berpengaruh secara bermakna.

Saran bagi peneliti yang tertarik dalam bidang yang sama, perlu dipertimbangkan pengaruh kepuasan pasien dan lingkungan internal individu terhadap citra Rumah Sakit dan perlu diteliti lebih lanjut mengenai atribut lokasi apa saja yang paling dibutuhkan pasien di RS. Paru Dr.H.A.Rotinsulu.

Mengingat lokasi RS. Paru Dr.H.A. Rotinsuliu relatif sulit dijangkau, maka untuk memenuhi tuntutan masyarakat yang membutuhkan pelayanan kesehatan sebaiknya RS. Paru Dr.H.A. Rotinsulu melakukan pelayanan pro aktif seperti pelayanan dirumah pasien (home care) dan memperbaiki kondisi transportasi serta jalan ke RS. Paru Dr.H.A. Rotinsulu seperti menyiapkan mobil hantar untuk pasien dan kerjasama dengan lingkungan setempat untuk mentertibkan kemacetan dengan cara membenahi parkir mobil di pinggir jalan

Pihak Manajemen RS. Paru Dr.H.A. Rotinsulu perlu meningkatkan program promosi dengan melakukan aktivitas public relations yang lebih efektif dan berkesinambungan seperti kerjasama dengan Puskesmas dan penyuluhan kesehatan ke tingkat desa. Menghimbau kepada seluruh jajaran karyawan Rumah Sakit untuk merekomendasikan kerabat terdekat, teman dan tetangga agar memanfaatkan pelayanan kesehatan di RS. Paru Dr.H.A. Rotinsulu. Dalam rangka menghadapi persaingan, maka RS. Paru Dr.H.A. Rotinsulu perlu menciptakan keunggulankeunggulan terutama dalam kualitas pelayanan serta perlu diinformasikan ke pelanggan atau 
masyarakat, sehingga daya saing dan daya tarik RS. Paru Dr.H.A. Rotinsulu dapat ditingkatkan agar akses masyarakat terhadap RS. Paru Dr.H.A. Rotinsulu semakin lebih baik.

\section{DAFTAR PUSTAKA}

1. Peraturam menteri kesehatan nomor:250/MENKES/Per/III/2008 Tentang Organisasi dan Tata Kerja Rumah Sakit Paru Dr.H.A. Rotinsulu

2. Aaker, David A. Building Strong Brand. Newyork:Library of congres cataloging in publication data, 1996:7-109.

3. Anwar Prabu Mangkunegara. Perilaku Konsumen. Bandung:PT Eresco, 1998:3,46-47.

4. Burnet, John J. Promotion Strategic. 3 rd ed. New Jersey:Prentice Hall, A Division of Simon and Scusters, 1993:6

5. Berry, Leonard L, Parasuraman A. Marketing Service. New York: Macmilan inc, 1998:28

6. Engel James F, Blacwell R D, Minicard P.W. Perilaku Konsumen. Jakarta:Binarupa Aksara, 1997:18-194.

7. Erick N. Berkowitz. Essentials of Health Care Marketing. London:Jones and Bartlett Publishers International, 2004:4

8. Lovelock Christopher, Wrigh Lauren. Prinsiples Service Marketing and Management. 2 nd ed. New Jersey:Pearson Education, 2002.

9. Hasbullah Thabrany. Rumah Sakit BUMN melanggar konstitusi. MARSI 2003;4:155.

10. Husen Umar. Riset Pemasaran dan prilaku konsumen. Jakarta:PT Gramedia Pustaka Utama, 2000:50

11. Keputusan Menteri Kesehatan Nomor HK.02.02/Menkes/52/2015 Tentang Rencana Strategis Kementerian Kesehatan 2015-2019

12. Payne,Andriane. The Essence of Service Marketing. United Kingdom:Prernticce Hall inc, 1993:154-129.

13. Peraturan Presiden Nomor 72 Tahun 2012 Tentang Sistem Kesehatan Nasional

14. Phillip Kotler, Amstrong, Gary. Priciple of Marketing. 5 th ed. New Jersey:Prentice Hall, 2000:47

15. Philip Kotler. Marketing Management. 11 th ed. New Jersey:Prentice Hall, 2003:135-303.

16. Phillip Kotler. Manajemen Pemasaran. Edisi 11. Jakarta:PT Indeks, 2005:418-451.

17. Rejeki S,(2016) Pengaruh Bauran Pemasaran Terhadap Kepuasan Dan Loyalitas Pasien Rawat Inap Di Rumah Sakit Umum Daerah Dr Soediran Mangun Sumarso Kabupaten Wonogiri, Journal of Human Resources Management and Organizational Behavior Vol. 1 No. 2 ISSN 1979-2700

18. Roland T Rust, A J Zahorik, T L Keiningham. Service Marketing. New York: Harper Collins College, 1996:10-11. 
19. Soejadi. Efisiensi Pengelolaan Rumah Sakit. Edisi 2. Jakarta:Katiga Bina, 1985.

20. Shiffman, Leon G, Leslie Lazar Kanuk. Consumer Behaviour. 6 th ed. New Jersey:Prentice Hall, 1997:10,323-440. 